\title{
Overexpression of hypoxia-inducible factor $1 \alpha$ induces migration and invasion through Notch signaling
}

\author{
QUAN TIAN $^{1}$, YAN XUE $^{1}$, WEI ZHENG $^{1}$, RONG SUN $^{1}$, WEI JI ${ }^{1}$, XINYANG WANG ${ }^{2}$ and RUIFANG AN ${ }^{1}$ \\ Departments of ${ }^{1}$ Gynecology and Obstetrics, and ${ }^{2}$ Urology, The First Affiliated Hospital \\ of Xi'an Jiaotong University, Xi'an 710061, P.R. China
}

Received April 22, 2015; Accepted May 29, 2015

DOI: $10.3892 /$ ijo.2015.3056

\begin{abstract}
Choriocarcinoma (CC) is the highest malignant gestational trophoblastic tumor which causes high mortality without timely treatment. HIF-1 $\alpha$ is a very important molecule promoting neoplasm aggressiveness, metastasis through the induction of the epithelial to mesenchymal transition (EMT). Several researches have shown that Notch signaling is necessary for coupling hypoxia to the EMT. However, the pathway in choriocarcinoma remains undetermined. In this study, overexpression of HIF-1 $\alpha$ inhibited epithelial index E-cadherin, cytokeratin 18 (CK18) and cytokeratin 19 (CK19) in two choriocarcinoma cell lines (JAR and JEG-3, respectively). The reciprocal changes associated with the EMT phenotypic transformation. The migration and invasive capability was significantly enhanced. HIF-1 $\alpha$ overexpression was positively correlated with Notch1 and Hes1 $(\mathrm{P}<0.01$; respectively). Using DAPT (Notch1 inhibitor) to knock down Notch1 expression, morphological and molecular typical changes of the EMT were detected in vitro. Knockdown of Notch1 prominently reduced MMP2 and MMP9 activities, and increased E-cadherin, CK18 and CK19 expression in JAR and JEG-3 cells $(\mathrm{P}<0.01)$. In vivo, serum-free suspension containing $5 \times 10^{6}$ JAR cells (lv-HIF-1 $\alpha$ and $1 v-N C$, respecticely) were implanted subcutaneously or injected intravenously into female NOD SCID mice, which were injected with DAPT or DMSO six times at 3-day intervals. Mice with subcutaneous nodules were injected i.v. fluorine-18 fluorodeoxyglucose $\left({ }^{18} \mathrm{~F}\right.$ FDG) and then scanned in small animal PET/CT (SA-PET/ $\mathrm{CT}$ ), and mice with lung metastasis were monitored by using the in vivo imaging system (IVIS). The in vivo data showed that inhibition of Notch signaling by DAPT treatment effectively suppressed metastatic tumor growth, metabolic activity and invasion. In summary, overexpression of HIF-1 $\alpha$ promotes choriocarcinoma cell aggressiveness and metastasis through
\end{abstract}

Correspondence to: Dr Ruifang An, Department of Gynecology and Obstetrics, The First Affiliated Hospital of Xi'an Jiaotong University, Xi'an 710061, P.R. China

E-mail: anruifang2015@163.com

Key words: HIF-1 $\alpha$, mesenchymal transition, Notch1, DAPT, choriocarcinoma, MMP the regulation of the EMT dependenting on Notch signaling pathway.

\section{Introduction}

Choriocarcinoma (CC) is a unique malignant gestational trophoblastic tumor that occurs primarily in women of reproductive age and is extremely prone to brain and/or lung metastasis. $\mathrm{CC}$ can be derived either from a normal or pathological pregnancy, such as molar pregnancies, ectopic pregnancies, induced/spontaneous abortions and preterm deliveries (1). Despite established first-line chemotherapy, $10-20 \%$ of CC patients presented drug-resistantance, or relapsed due to solitary metastasis lesions. Thus, to understand the underlying recurrence and metastasis mechanisms of $\mathrm{CC}$ remains crucial.

Hypoxia has a critical role in carcinogenesis, tumor progression, distant metastasis, angiogenesis and resistance to chemotherapy and radiation therapy $(2,3)$. When oxygen demand of solid tumors exceed the oxygen-supplying capacity of the vasculature, hypoxia is primarily mediated through hypoxia inducible factors (HIFs) (4). HIFs comprise oxygensensitive $\alpha$-subunit (HIF-1 $\alpha$, HIF-2 $\alpha$ and HIF-3 $\alpha$ subunits) and constitutively express $\beta$-subunit (HIF- $\beta$, known as ARNT). When stabilized in hypoxia, the remarkably high expression of HIF- $1 \alpha$ dimerizes with HIF- $\beta$ and activates downstream genes involved in the canonical hypoxic response via HRE elements in their promoters $(5,6)$. Regulated post-translationally in normoxia, HIF-1 $\alpha$ is rapidly degraded through the von Hippel-Lindau (VHL)-dependent ubiquitin-proteasome pathway (7).

It has been reported that the initiation of metastasis involves EMT-like processes (8). EMT transforms tumor cells from a polar, epithelial morphology to mesenchymal and invade tissues (8). The EMT renders a more aggressive phenotype with enhanced invasiveness and proliferation, formation of metastases and higher mortality (9). Substantial evidence demonstrates that activation of hypoxic signaling through HIFs is triggered by modulators of EMT, which is accompanied by specific changes in gene expression, such as downregulation of E-cadherin, CK18, CK19 (10-14). Notably, Snail-1, the zinc finger transcription factor, represses the E-cadherin promoter and effectively induces EMT (15). However, the molecular mechanisms between hypoxia and EMT are still elusive. 
In mammals, the Notch signaling pathway involving differentiation, proliferation, and survival, comprise a series of ligands (Jagged-1 and -2, Delta-1, -3, and -4) and transmembrane receptors (Notch-1 to -4) (16). When ligand has integrated the Notch receptor susceptible to cleavage, initially by TACE (TNF- $\alpha$ converting enzyme) and then by the $\gamma$-secretase complex, which ultimately take the form of the activated Notch intracellular domain (NICD). NICD enters the nucleus and interacts with the DNA-binding protein CSL to regulate expression of downstream genes, such as Hes and Hey (17).

Recently, connection between Notch signaling and hypoxia was demonstrated in the control of cell proliferation, stem cell differentiation and angiogenesis of missed abortion (18-20). It was also indicated that Jagged-1 and DLL1 induces EMT through repression of E-cadherin $(21,22)$. Furthermore, several studies demonstrated that Notch signaling mediated molecular mechanisms underlying HIF-dependent regulation of the EMT in ovarian carcinoma, breast cancer and melanoma, respectively (22-24). Thus, we propose that the Notch signaling pathway is a valuable candidate as a mediator between hypoxia and EMT in CC cells. Hence, our study stably overexpressed HIF-1 $\alpha$ by Lentiviral vector to examine the effects of HIF-1 $\alpha$ on migration and invasion, and the HIF-1 $\alpha /$ Notch/EMT pathway in CC cells. We provide evidence for the role of Notch as a crucial mediator of HIF-1 $\alpha$ in enhanced tumor migration and invasiveness.

\section{Materials and methods}

Cell culture. The human first trimester extravillous trophoblast (EVT) cell line (HTR-8) cultured in DMEM/F12 and two human CC cell lines (JAR and JEG-3) cultured in DMEM were obtained from the American Type Culture Collection (Manassas, VA, USA). These cells were supplemented with $10 \% \mathrm{FBS}$ and incubated in a $37^{\circ} \mathrm{C}$ humidified incubator containing $5 \% \mathrm{CO}_{2}$. Notch activity was blocked by a $10 \mu \mathrm{M}$ concentration of DAPT (Sigma, St. Louis, MO, USA), added at each day of culturing.

RNA extraction and real-time PCR. Total RNA was extracted from above-mentioned cell lines according to RNeasy Mini kit (Qiagen, USA) manufacturer's protocol and quantitated by spectrophotometry. According to the manufacturer's protocol, mRNA was then reverse transcribed using Revert Aid $^{\mathrm{TM}}$ First Strand cDNA Synthesis kit (MBI Fermentas, St. Leon-Rot, Germany). The SYBRR Premix Ex Taq ${ }^{\mathrm{TM}}$ II system (Takara, Dalian, China) and the Bio-Rad CFX96 ${ }^{\mathrm{TM}}$ Real-time system (Bio-Rad, CA, USA) were used to perform real-time quantitative PCR. Following the reverse transcription, $1 \mu \mathrm{l}$ primer $(10 \mu \mathrm{M}$, summarized in Table I), $12.5 \mu \mathrm{l}$

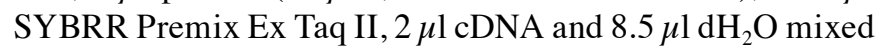
together, pre-degeneration for $95^{\circ} \mathrm{C}, 30 \mathrm{sec}$, one repeat, and PCR reaction, $95^{\circ} \mathrm{C} 5 \mathrm{sec}$ followed by $60^{\circ} \mathrm{C}, 30 \mathrm{sec}, 35$ repeats, and the dissociation stage, $95^{\circ} \mathrm{C}, 15 \mathrm{sec}$ followed by $60^{\circ} \mathrm{C}$, $30 \mathrm{sec}$, and $95^{\circ} \mathrm{C}, 15 \mathrm{sec}$, then the data were collected and analyzed. $\beta$-actin (25) was used as the internal control. The threshold cycle $(\mathrm{Ct})$ value for triplicate reactions was averaged. Melting curve for the primers was analyzed to confirm the specificity of the PCR product. The relative expression of
mRNA for each target gene was calculated as follows: $\Delta \mathrm{Ct}=$ $\mathrm{Ct}($ target $)-\mathrm{Ct}(\beta$-actin $), \Delta \Delta \mathrm{Ct}=\Delta \mathrm{Ct}-\Delta \mathrm{Ct}$ (calibrator), and the fold changes in $\mathrm{mRNAs}$ were calculated through relative quantification $\left(2^{-\Delta \Delta C t}\right)$.

Western blotting. Cells were harvested at $80-90 \%$ confluence, and washed with $4^{\circ} \mathrm{C}$ PBS three times. Total cellular protein lysates were reconstituted with RIPA buffer [50 mM Tris ( $\mathrm{pH} 8.0$ ), $0.1 \% \mathrm{SDS}, 150 \mathrm{mM} \mathrm{NaCl}, 1 \% \mathrm{NP} 40$ and $0.5 \%$ sodium deoxycholate] and proteinase inhibitors [1 $\mathrm{mM}$ PMSF (Sigma)]. The denatured protein samples was separated by SDS-PAGE and electrophoretically transferred to nitrocellulose (NC) membranes. The NC membranes were blocked with $5 \%$ skim milk at room temperature for $1 \mathrm{~h}$, then incubated in different monoclonal or polyclonal antibodies with different dilutions by $5 \% \mathrm{BSA}$ overnight at $4^{\circ} \mathrm{C}$ and washed with TBST three times (with Tween-20, pH 7.6). Subsequently, membranes were incubated in secondary antibodies (Licor, Rockford, IL, USA) in the dark for $1 \mathrm{~h}$. The NC membranes were scanned with Odyssey detection system (Licor). MG-132 (Sigma) was applied to inhibit the proteasome-dependent degradation if necessary $(10 \mu \mathrm{M}, 4 \mathrm{~h}$ before the protein harvest) (26). $\beta$-actin (25) were used as the loading controls.

Production and transfection of lentivirus-mediated vectors. The NCBI accession number for the Homo sapiens HIF-1 $\alpha$ gene sequence is NM_001530.3. The CDS of HIF-1 $\alpha$ was used to construct lentiviral vectors. HIF-1 $\alpha$ cDNA was amplified and cloned into the lentiviral (lv) vector GV358 (Genechem, Shanghai, China), a lentiviral vector encoding the enhanced green fluorescent protein (EGFP) gene cDNA downstream of the ubi promoter (Lenti-ubiluc). To prepare lentiviral particles, the lentiviral vector overexpressing HIF-1 $\alpha$ gene (lv-HIF-1 $\alpha$ ), pHelper 1.0 plasmid and pHelper 2.0 helper plasmid were co-transfected into $293 \mathrm{~T}$ cells according to the manufacturer's protocol. The lentiviral vector were used to infect JAR and JEG-3 cells at a multiplicity of infection (MOI) of 40 and 100, respectively. Lentivirus vectors only expressing EGFP gene (lv-NC) was used as a transfection control. Seventy-two hours after infection, EGFP expression was observed to evaluate the infection efficiency. Cells were harvested $96 \mathrm{~h}$ after infection. The expression level of HIF-1 $\alpha$ was examined by qPCR and western blotting. These transfectants were selected by 2 or $1 \mu \mathrm{g} / \mathrm{ml}$ puromycin respectively (Sigma) to establish the stable clone cell lines and analyze with fluorescent microscopy. After the DAPT treatment was performed, the cells were harvested for further analysis.

Scratch wound assay. To assay cell migration, JAR and JEG-3 cells after lentiviral transfection (lv-HIF-1 $\alpha$ and lv-NC) were scratched in 6-well plates with pipette tip when the cells were at $80 \%$ confluence. Cells were incubated in serum-free medium, and the width of the scratches was measured at 0 and $24 \mathrm{~h}$ after scratching. DMSO $(0.1 \%)$ or $10 \mu \mathrm{M}$ DAPT was added to medium.

Invasion assays. Cell invasion were performed by Boyden chamber assay. The $8-\mathrm{mm}$ pore size upper chamber with $50 \mu \mathrm{l}$ 
Table I. Primers for real-time PCR.

\begin{tabular}{|c|c|c|c|}
\hline Gene ID & Gene & & Primers \\
\hline NM_005524.3 & Hes 1 & $\begin{array}{l}\text { Forward } \\
\text { Reverse }\end{array}$ & $\begin{array}{l}\text { AGGCGGACATTCTGGAAATG } \\
\text { TCGTTCATGCACTCGCTGA }\end{array}$ \\
\hline NM_005985.3 & Snail-1 & $\begin{array}{l}\text { Forward } \\
\text { Reverse }\end{array}$ & $\begin{array}{l}\text { ATCCCTGGAAGCTGCTCTCT } \\
\text { TCTGGTCCAGTGAGGGAG }\end{array}$ \\
\hline NM_004360.3 & E-cadherin & $\begin{array}{l}\text { Forward } \\
\text { Reverse }\end{array}$ & $\begin{array}{l}\text { GGDCTGAAGTGACTCGTAACGA } \\
\text { CAGCCGCTTTCAGATTTTCATC }\end{array}$ \\
\hline NM_000224.2 & CK18 & $\begin{array}{l}\text { Forward } \\
\text { Reverse }\end{array}$ & $\begin{array}{l}\text { GGCATCCAGAACGAGAAGGAG } \\
\text { ATTGTCCACAGTATTTGCGAAGA }\end{array}$ \\
\hline NM_002276.4 & CK19 & $\begin{array}{l}\text { Forward } \\
\text { Reverse }\end{array}$ & $\begin{array}{l}\text { AACGGCGAGCTAGAGGTGA } \\
\text { GGATGGTCGTGTAGTAGTGGC }\end{array}$ \\
\hline NM_001530.3 & $\mathrm{HIF}-1 \alpha$ & $\begin{array}{l}\text { Forward } \\
\text { Reverse }\end{array}$ & $\begin{array}{l}\text { GTGTTATCTGTCGCTTTGAGTC } \\
\text { GTCTGGCTGCTGTAATAATGTT }\end{array}$ \\
\hline NM_001197325.1 & HIF-1 $\beta$ (ARNT) & $\begin{array}{l}\text { Forward } \\
\text { Reverse }\end{array}$ & $\begin{array}{l}\text { CTGCCAACCCCGAAATGACAT } \\
\text { CGCCGCTTAATAGCCCTCTG }\end{array}$ \\
\hline NM_017617.3 & Notch1 & $\begin{array}{l}\text { Forward } \\
\text { Reverse }\end{array}$ & $\begin{array}{l}\text { AAGCTGCATCCAGAGGCAAAC } \\
\text { TGGCATACACACTCCGAGAACAC }\end{array}$ \\
\hline NM_001127891.2 & MMP2 & $\begin{array}{l}\text { Forward } \\
\text { Reverse }\end{array}$ & $\begin{array}{l}\text { TACAGGATCATTGGCTACACAC } \\
\text { GGTCACATCGCTCCAGACT }\end{array}$ \\
\hline NM_004994.2 & MMP9 & $\begin{array}{l}\text { Forward } \\
\text { Reverse }\end{array}$ & $\begin{array}{l}\text { TGTACCGCTATGGTTACACTCG } \\
\text { GGCAGGGACAGTTGCTTCT }\end{array}$ \\
\hline NM_001101.3 & $\beta$-actin & $\begin{array}{l}\text { Forward } \\
\text { Reverse }\end{array}$ & $\begin{array}{l}\text { AAGAGATGGCCACGGCTG } \\
\text { GAACCGCTCATTGCCAATG }\end{array}$ \\
\hline
\end{tabular}

Matrigel (Sigma) was incubated for $4 \mathrm{~h}$. For migration, the serum-free medium suspension with $5 \times 10^{4}$ cells was added in the upper chamber, and $800 \mu 1$ medium with $20 \%$ serum was added in the lower chamber of 24 -well plate. Cells $\left(5 \times 10^{4} /\right.$ well) were seeded in the same medium in a well without chamber simultaneously. $0.1 \%$ DMSO or $10 \mu \mathrm{M}$ DAPT was added to medium in upper and lower chambers. After $24 \mathrm{~h}$, the chambers were washed with PBS (pH 7.4) three times. The non-invaded cells of upper surface in chamber were removed with a cotton swab. The cells of lower surface was fixed with $4 \%$ formalin for $10 \mathrm{~min}$, then stained with crystal violet $(0.01 \%$ in ethanol, Sigma) for $20 \mathrm{~min}$ followed by PBS washing three times. Five random visions were taken by inverted microscope, and the cell number was counted.

In vivo growth and metabolic activity assay. Considering that the JAR cell line is more easily infected by lentiviruses than the JEG-3 cell line (unpublished data), the JAR cells transfected with lv-NC or lv-HIF-1 $\alpha$ were used in vivo. Cells were cultured and collected in a single-cell suspension in PBS (pH 7.4). Suspension (200 $\mu \mathrm{l})\left(5 \times 10^{6} \mathrm{lv}-\mathrm{NC}\right.$ or $\mathrm{lv}-\mathrm{HIF}-1 \alpha$ cells) was implanted under the dorsal skin of 4- to 6-weekold female SCID mice to form a subcutaneous tumor. Based on the references (27-29) and previous studies, the mice were randomly divided into four groups $(n=5)$ : i) JAR (lv-NC) treated with $0.1 \%$ DMSO diluted with saline; ii) JAR (lv-NC) treated with DAPT $(10 \mathrm{mg} / \mathrm{kg})$; iii) JAR (lv-HIF-1 $\alpha)$ treated with $0.1 \%$ DMSO diluted with saline; iv) JAR (lv-HIF-1 $\alpha$ ) treated with DAPT $(10 \mathrm{mg} / \mathrm{kg})$. The mice were treated with DAPT or DMSO intraperitoneally six times at 3-day intervals (on days 1, 4, 7, 10, 13 and 16). Tumors were observed for growth, swelling, and diabrosis, and the tumor volumes were measured daily. The following experiment was conducted when the tumors reached $15-75 \mathrm{~mm}^{3}$ in size.

All mice were induced with $4 \%$ isoflurane and maintained on $2-2.5 \%$ isoflurane in preparation for SA-PET/CT scans. Subsequently, ${ }^{18}$ F-FDG tracer were injected intravenously under general anesthesia. The PET/CT imaging was carried out for evaluation of uptake in the subcutaneous tumors (30). A CT scan was obtained for reconstruction and further analysis of the PET/CT data. Standardized uptake value (SUV) were used to compare variations among groups.

In vivo invasion and metastasis assay. To establish a model for monitoring of Notch signaling in choriocarcinoma metastasis, the JAR cells transfected with lv-NC or lv-HIF-1 $\alpha(200 \mu 1$, $5 \times 10^{6}$ cells) were injected intravenously into femal SCID mice. The groups and treatment were the same as the growth assay. Their metastasis was monitored by using In Vivo Imaging System (IVIS; Xenogen, Alameda, CA, USA) at the end of treatment. Animal studies were approved by the Ethics Committee of our Hospital. 
A
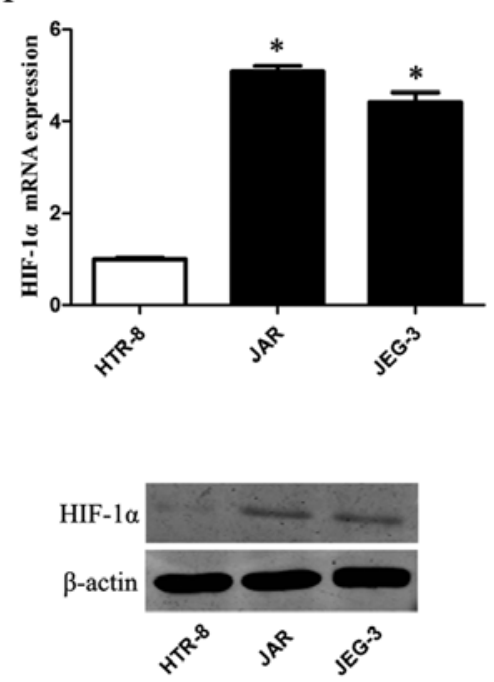

B

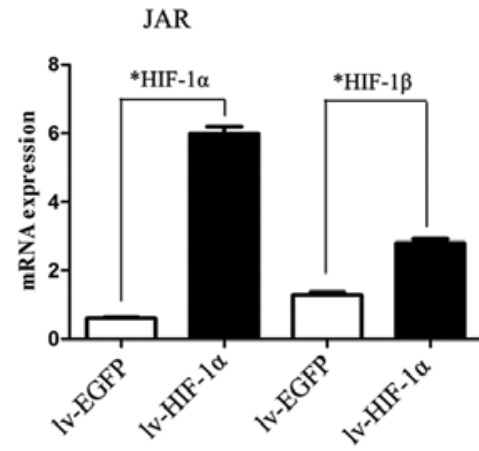

JAR

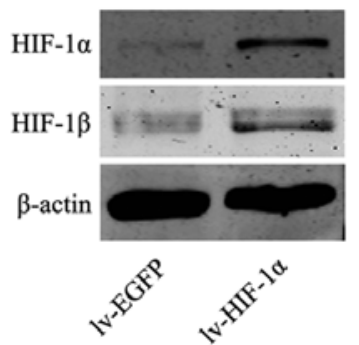

$\mathrm{C}$

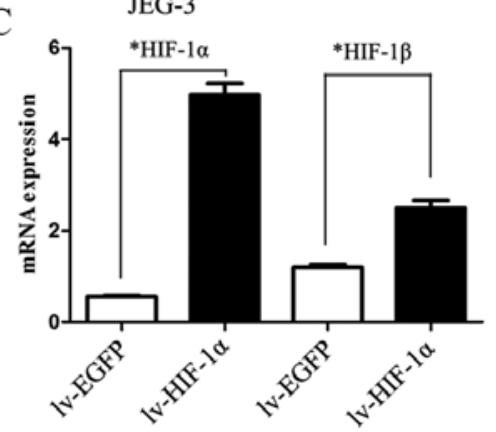

JEG-3

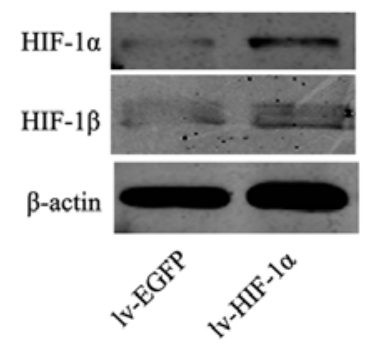

Figure 1. The expression of HIF-1 $\alpha$ in cell lines and upregulation of HIF-1 $\alpha$ accompanied by the elevation of HIF-1 $\beta$. (A) HIF-1 $\alpha$ expression in the normal human extravillous trophoblast cell line (HTR-8) and two choriocarcinom cell lines (JAR and JEG-3) ( $\mathrm{n}=3$, * $\mathrm{P}<0.01$, vs. HTR-8 group, respectively). (B) Upregulation of HIF-1 $\alpha$ promotes corresponding HIF-1 $\beta$ expression on mRNA and protein level in JAR cells $\left(n=3\right.$, $\left.{ }^{*} \mathrm{P}<0.01\right)$. (C) Upregulation of HIF-1 $\alpha$ promotes corresponding HIF- $\beta$ expression on mRNA and protein level in JEG-3 cells $\left(n=3,{ }^{*} \mathrm{P}<0.01\right)$.

Statistical analysis. Each of the experiments were performed in triplicate and repeated three times. Statistical analysis was carried out using the SPSS 18.0 statistical software package (SPSS Inc., Chicago, IL, USA). Summary data are showed as means \pm SEM. Group means were compared using the appropriate version of the Student's unpaired t-test. P-values were 2 -sided. Test results were considered significant at $\mathrm{P}<0.05$.

\section{Results}

HIF-1 $\alpha$ is upregulated in choriocarcinoma cells. We examine the mRNA and protein expression levels of HIF-1 $\alpha$ in CC cell lines and HTR-8. The expression levels of HIF-1 $\alpha$ were markedly upregulated in JAR and JEG-3 cells, as compared to the expression level of a control HTR-8 cell line (Fig. 1A, $\mathrm{P}<0.01$ ).

Upregulation of HIF-1 $\alpha$ enhances EMT and the ability of migration/invasion, accompanied by the elevation of HIF-1 $\beta$. To mimic the hypoxic microenvironment and further define our understanding of HIF-1 $\alpha$ in choriocarcinoma, JAR and JEG-3 cells were transfected with lentivirus of HIF-1 $\alpha$ (lv-HIF-1 $\alpha)$ to establish stable cell lines that upregulated expression of HIF-1 $\alpha$ in CC cells. Simultaneously, EGFP expression was observed in $\mathrm{CC}$ cells transfected with the corresponding lv-NC. Compared to the lv-NC cells, the mRNA and protein level of HIF- $1 \alpha$ were significantly upregulated in $1 \mathrm{v}-\mathrm{HIF}-1 \alpha$ cells $(\mathrm{P}<0.01$, respectively, Fig. 1B and C). Consistently, upregulation of HIF-1 $\alpha$ promotes corresponding HIF-1 $\beta$ expression on mRNA and protein level $(\mathrm{P}<0.01)$.

In order to investigate whether HIF-1 $\alpha$ induces EMT of CC cells, inverted microscopy was used revealing that Lv-HIF-1 $\alpha$ cells formed a spindle-like monolayer with more elongated and larger gaps between cells than lv-NC cells which formed a cobblestone-like monolayer (Fig. 2A). Western blot analyses further confirmed that the EMT phenotype is induced by overexpression of HIF-1 $\alpha$ in CC cells. HIF-1 $\alpha$ markedly decreased E-cadherin, CK-18 and CK-19 expression in lv-HIF-1 $\alpha$ cells, the reciprocal changes associated with the EMT phenotypic transition $(\mathrm{P}<0.01$, respectively, Fig. $2 \mathrm{~B}$ and $\mathrm{C})$.

To study HIF-1 $\alpha$-induced EMT with malignant behavior, the scratch wound-healing assay and Matrigel membrane invasion assay were used. The extent of migration of $\mathrm{CC}$ cells with exogenous HIF-1 $\alpha$ into the scratched area was elevated (Fig. 3A, P<0.05). Similarly, the invasive capability was significantly enhanced when HIF-1 $\alpha$ was upregulated (Fig. 3B, P<0.05). Consistent with the data, MMP2 and MMP9 were upregulated by HIF-1 $\alpha$ overexpression (Fig. 3C, $\mathrm{P}<0.01$ ).

HIF-1 $\alpha$-induced upregulation of NIICD and Hesl was abolished by DAPT. The elevated Notch response after mimicked hypoxia was observed at two levels in the Notch signaling pathway. On the receptor side, the level of N1ICD was elevated in JAR cells subjected to HIF-1 $\alpha$. On the downstream side, upregulation of Hes1 mRNA and protein was observed in CC cells, simultaneously ( $\mathrm{P}<0.01$, Fig. $4 \mathrm{~A})$. The DAPT data would suggest that the inhibitor blocked the conformation of N1ICD protein to abrogate Notch signaling, then Hes1 mRNA and protein were decreased in JAR cells $(\mathrm{P}<0.01$, Fig. 4A). Similar data were obtained for the JEG-3 cell line $(\mathrm{P}<0.01$, Fig. 4B).

HIF-1 $\alpha$ induces EMT through Notch signaling. To evaluate the involvement of Notch in HIF-1 $\alpha$-induced EMT in CC cells, $0.1 \%$ DMSO or $10 \mu \mathrm{M}$ DAPT was added in culture medium. 

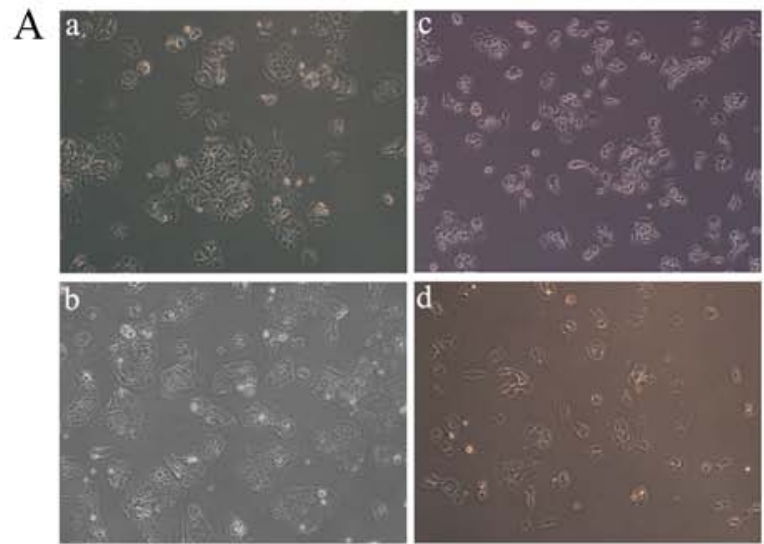

B

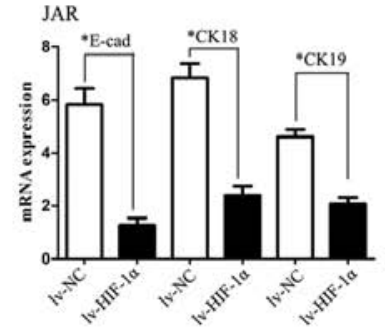

JAR

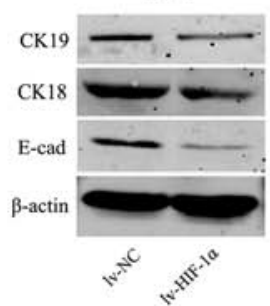

$\mathrm{C}$

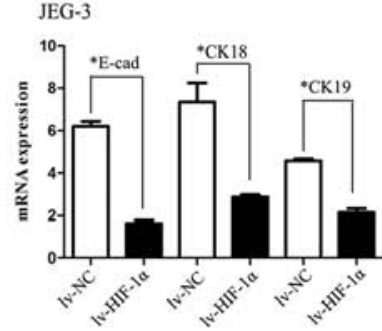

JEG-3

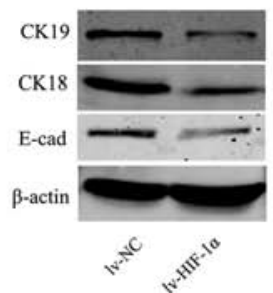

Figure 2. Upregulation of HIF-1 $\alpha$ induces EMT of choriocarcinom cells. (A) lv-NC cells formed a cobblestone-like monolayer, which is typically epithelial cells ( $b$ and d); Lv-HIF-1 $\alpha$ cells formed a spindle-like monolayer with larger gaps between cells that were more elongated than lv-NC cells (a and c). (B) HIF-1 $\alpha$ overexpression markedly decreased E-cadherin, CK-18 and CK-19 expression in JAR cells $\left(n=3,{ }^{*} \mathrm{P}<0.01\right)$. (C) HIF-1 $1 \alpha$ overexpression markedly decreased E-cadherin, CK-18 and CK-19 expression in JEG-3 cells $\left(\mathrm{n}=3,{ }^{*} \mathrm{P}<0.01\right)$.

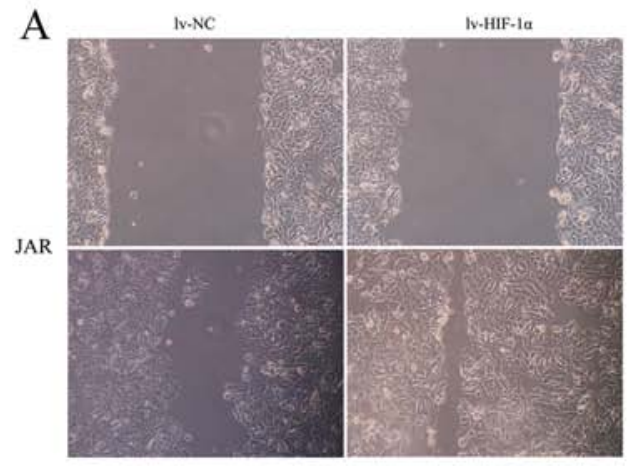

B

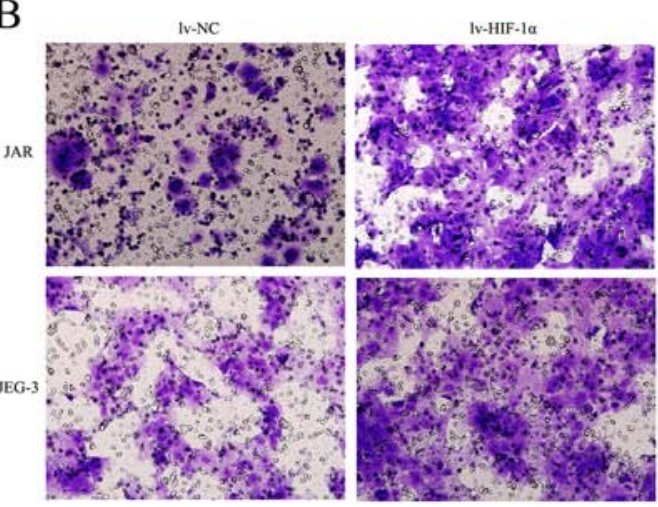

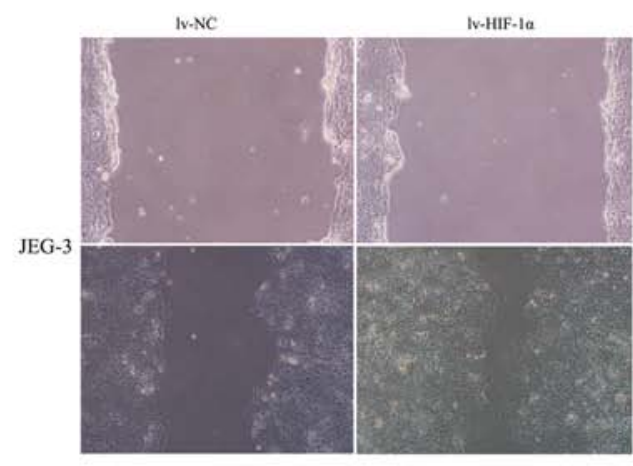

$\mathrm{C}$
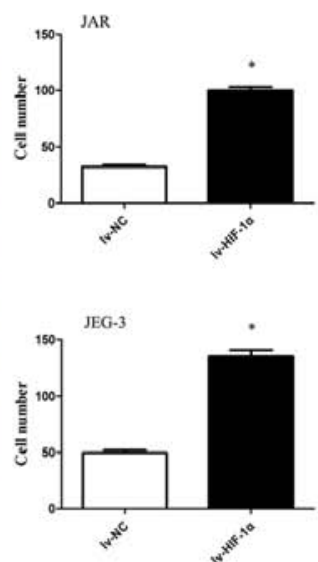
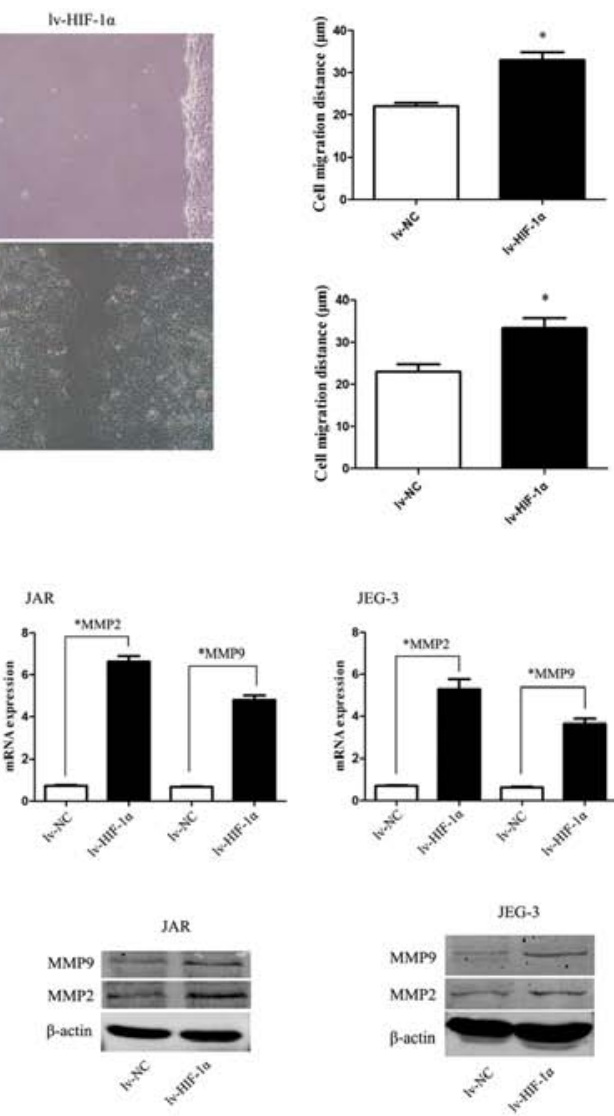

Figure 3. The effect of HIF-1 $\alpha$ overexpression on choriocarcinom cells. (A) Representative images show the migration ability of choriocarcinoma cells transfected with lv-NC or lv-HIF-1 $\alpha$. Data are presented as mean cell migration distance of repeat experiments ( $\mathrm{P}<0.01)$. (B) Representative images show the invasion ability of choriocarcinoma cells transfected with lv-NC or lv-HIF-1 $\alpha$. Data are presented as mean relative numbers of invaded or migrated cells $($ "P<0.01). (C) Choriocarcinoma cells transfected with lv-NC or lv-HIF-1 $\alpha$, respectively, were subjected to western blotting for MMP2 and MMP9 (P<0.01).

Inhibition of Notch signaling abolished the downregulation of E-cadherin, CK-18, CK-19 mRNA and protein levels observed in lv-HIF-1 $\alpha$ cells $(\mathrm{P}<0.01$, respectively, Fig. 5). Because Snail-1 is the crucial regulator of E-cadherin expression, the 
A
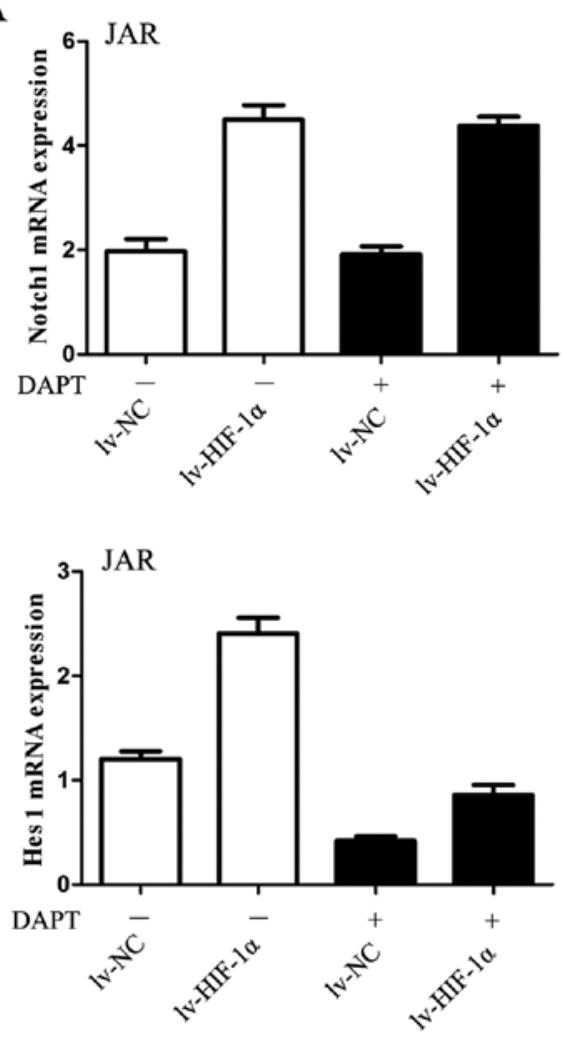

JAR

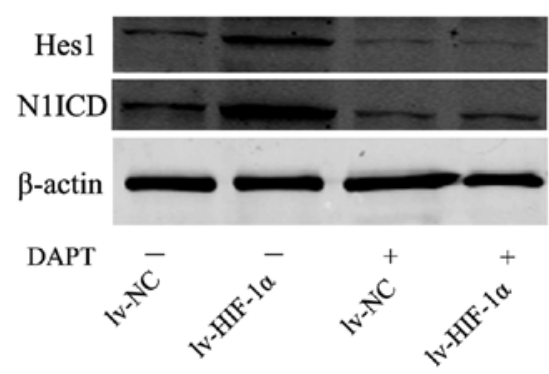

B
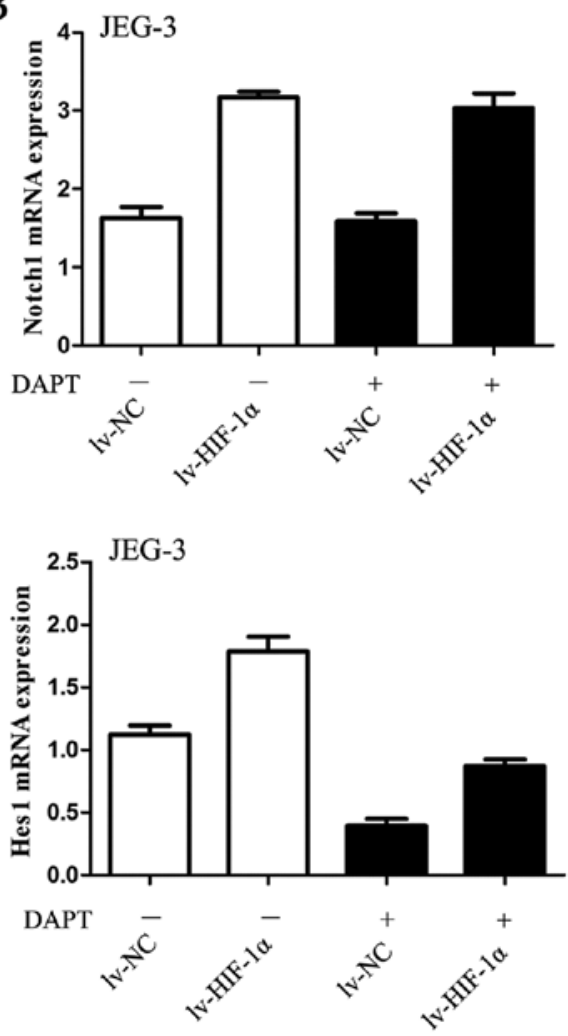

JEG-3

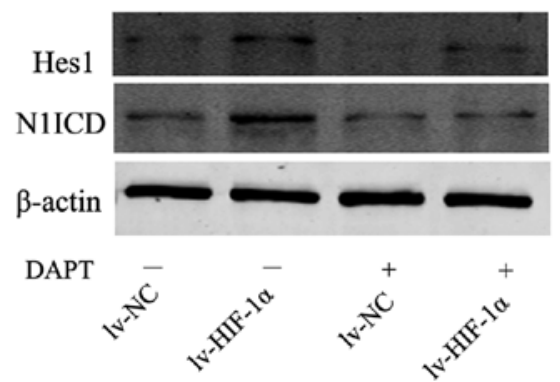

Figure 4. HIF-1 $\alpha$ overexpression induces increased expression of N1ICD and downstream choriocarcinoma cells can be abrogated by DAPT. (A) HIF-1 $\alpha$ overexpression upregulates Hes-1 mRNA and protein expression and N1ICD protein expression can be abrogated by DAPT in JAR cells (P<0.01). (B) HIF-1 $\alpha$ overexpression upregulates Hes-1 mRNA and protein expression and N1ICD protein expression can be abrogated by DAPT in JEG-3 cells (P<0.01).

Table II. The antibodies.

\begin{tabular}{lllll}
\hline Gene ID & \multicolumn{1}{c}{ Antibody } & Dilutions & Species & \multicolumn{1}{c}{ Supplied by } \\
\hline NM_005524.3 & Hes1 & $1: 600$ & Homo & Abcam \\
NM_005985.3 & Snail-1 & $1: 300$ & Homo & Santa Cruz \\
NM_004360.3 & E-cadherin & $1: 500$ & Homo & Santa Cruz \\
NM_000224.2 & CK18 & $1: 1000$ & Homo & Santa Cruz \\
NM_002276.4 & CK19 & $1: 200$ & Homo & Santa Cruz \\
NM_001530.3 & HIF-1 $\alpha$ & $1: 1000$ & Homo & Abcam \\
NM_001197325.1 & HIF-1 $\beta$ & $1: 500$ & Homo & Cell Signaling Technology \\
NM_017617.3 & Notch1 (N1ICD) & $1: 500$ & Homo & Abcam \\
NM_001127891.2 & MMP2 & $1: 200$ & Homo & Santa Cruz \\
NM_004994.2 & MMP9 & $1: 100$ & Homo & Santa Cruz \\
NM_001101.3 & $\beta$-actin & $1: 10,000$ & Homo & Santa Cruz \\
\hline
\end{tabular}


A
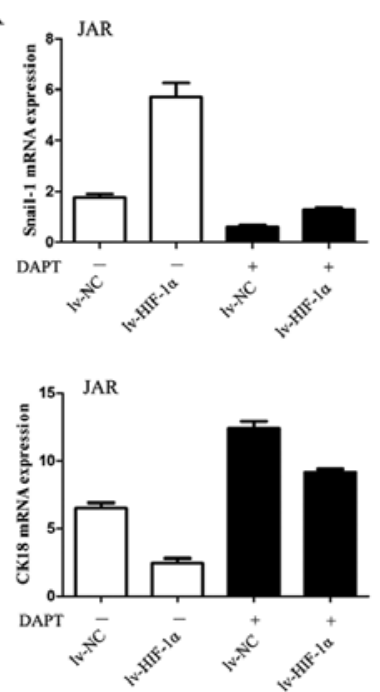

C

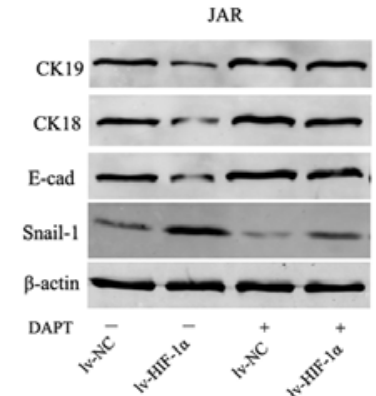

$\mathrm{B}$
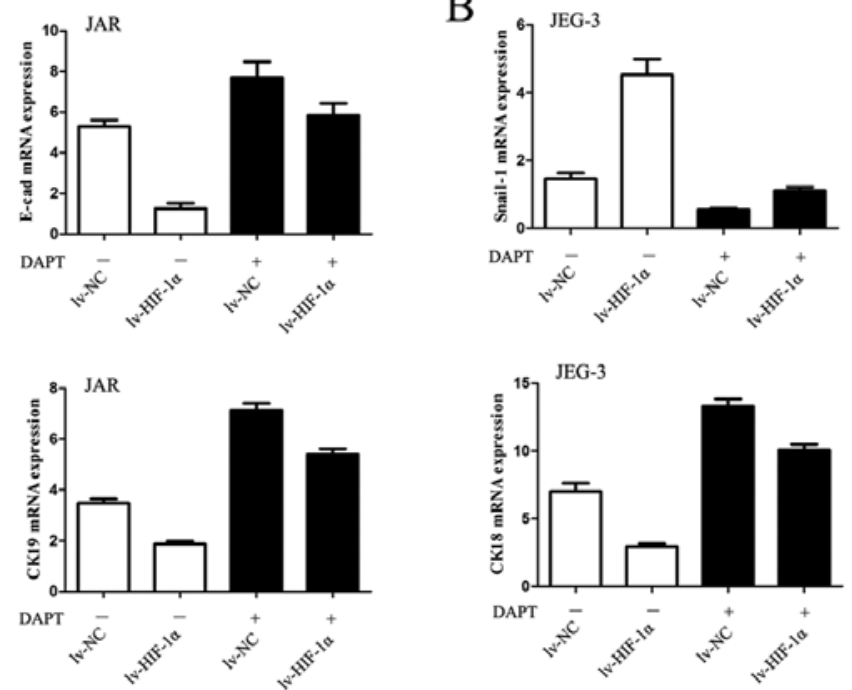

$\mathrm{D}$

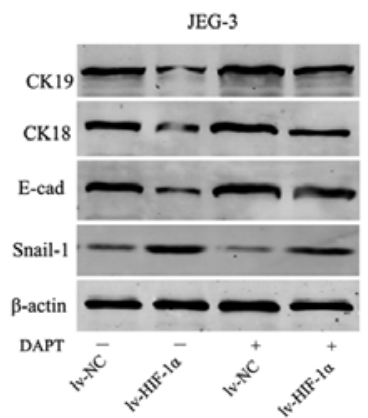

Figure 5. HIF-1 $\alpha$ overexpression induced EMT in choriocarcinoma cells can be abrogated by DAPT. (A) HIF-1 $\alpha$ overexpression upregulates Snai1 mRNA expression and downregulates E-cadherin, CK-18 and CK-19 mRNA expression can be abrogated by DAPT in JAR cells (P<0.01). (B) HIF-1 $\alpha$ overexpression upregulates Snai1 mRNA expression and downregulates E-cadherin, CK-18 and CK-19 mRNA expression can be abrogated by DAPT in JEG-3 cells (P<0.01). (C) HIF-1 $\alpha$ overexpression upregulates Snail protein expression and downregulates E-cadherin, CK-18 and CK-19 protein expression can be abrogated by DAPT in JAR cells $(\mathrm{P}<0.01)$. (D) HIF-1 $\alpha$ overexpression upregulates Snail protein expression and downregulates E-cadherin, CK-18 and CK-19 protein expression can be abrogated by DAPT in JEG-3 cells $(\mathrm{P}<0.01)$.

data would hint that E-cadherin expression is mediated via regulating Snail-1 at the transcriptional and protein level. Upregulation of Snail-1 by exogenous HIF-1 $\alpha$ was abrogated by DAPT treatment in CC cells $(\mathrm{P}<0.01$, Fig. 5).

HIF-1 $\alpha$-induced upregulation of MMPs requires Notch activation. Given the fundamental interaction between Notch signaling and HIF-1 $\alpha$-induced EMT with enhanced ability of migration/invasion, we considered whether HIF-1 $\alpha$-induced upregulation of MMPs require Notch signaling. The data revealed that MMP2 and MMP9 were upregulated by HIF-1 $\alpha$ but substantially blocked in the presence of DAPT $(\mathrm{P}<0.01$, respectively, Fig. 6).

DAPT inhibits choriocarcinoma growth and metabolic activity in vivo. To determine whether the observed antitumor activity in vitro by Notch inhibitors could be extended in vivo, DAPT was injected intraperitoneally into SCID mice with tumor xenografts of the JAR cells transfected with lv-NC or lv-HIF-1 $\alpha$ six times at 3-day intervals. Here, SA-PET/ CT scans of subcutaneous tumors were performed on mice and SUV of ${ }^{18} \mathrm{~F}-\mathrm{FDG}$ binding in vivo scans are provided in Fig. 7A. ${ }^{18} \mathrm{~F}-\mathrm{FDG}$ uptake in nodules of the lv-HIF-1 $\alpha$ mice treated with DMSO was high, while the nodules of lv-NC mice treated with DMSO were at low levels. DAPT-treated groups showed only slight ${ }^{18} \mathrm{~F}$-FDG activity in the tumors of the lv-NC group, unlike the high level of activity in the lv-HIF-1 $\alpha$ group (Fig. 7A). After PET/CT scans, we removed the red-brown transplantation tumor (Fig. 7B). The transplantation tumors grew in elliptical shapes with the purplish-black covering skin. The DMSO groups showed that HIF- $1 \alpha$ alone significantly promoted tumor growth. Compared with the DMSO group, DAPT treatment significantly inhibited tumor growth $(\mathrm{P}<0.05$, Fig. 7C).

DAPT inhibits choriocarcinoma invasion and metastasis in vivo. To assess the capacity of suppression of endogenous Notch signaling as a treatment for choriocarcinoma cell metastasis, JAR cells stably expressing EGFP were injected intravenously into SCID mice as an in vivo model of metastasis. In mice treated with DAPT or DMSO six times at 3-day intervals from the time of cell injection. Under IVIS system, macroscopic appearance of metastatic tumors were detected in lung of $85 \%(17 / 20)$ mice at 30 days after intravenous injection. Positive signals were detected in $100 \%(5 / 10,1 v-H I F-1 \alpha)$ and $100 \%(5 / 5, \mathrm{lv}-\mathrm{NC})$ of mice treated with DMSO, respectively. 
A
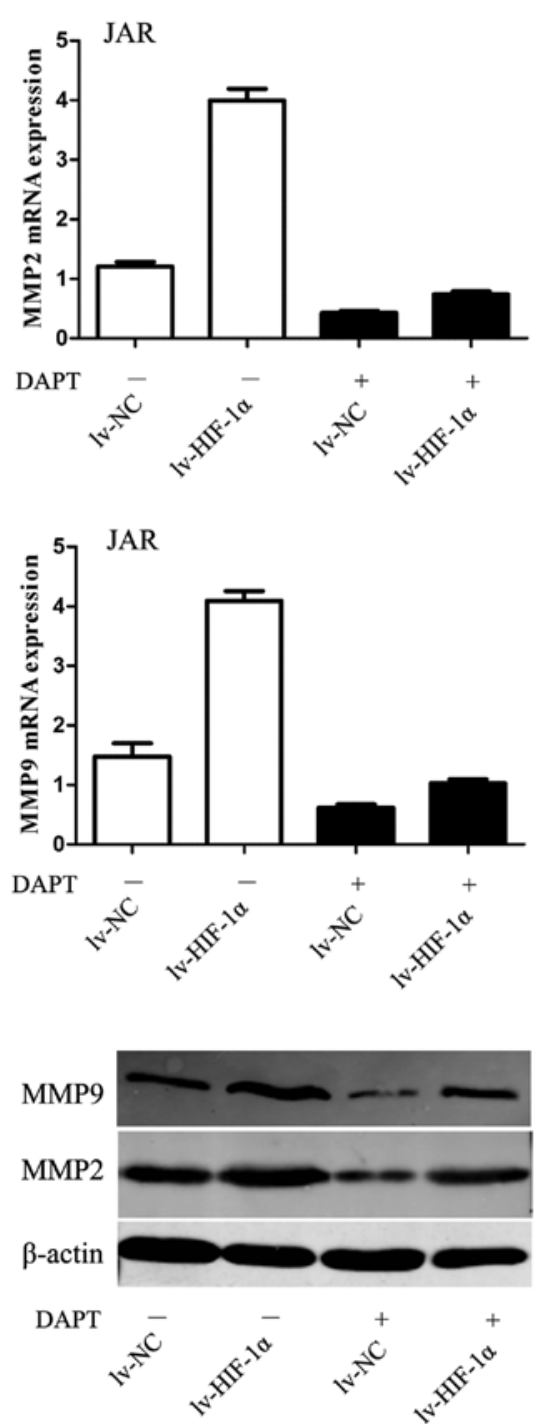

$\mathrm{B}$
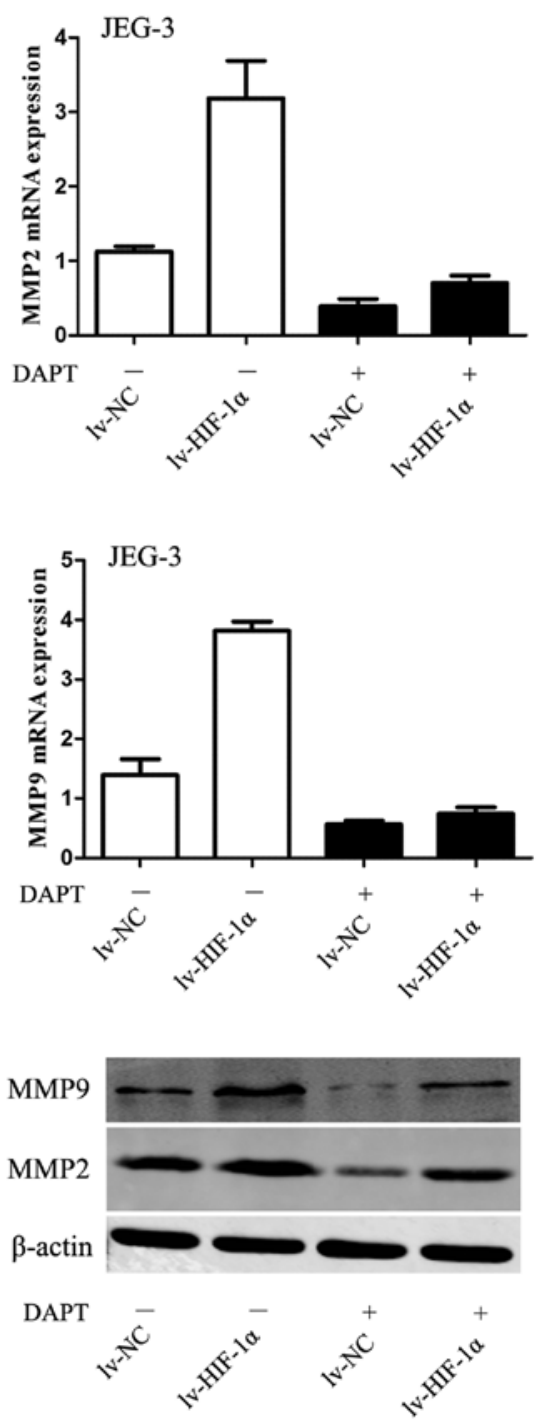

Figure 6. The effect of HIF-1 $\alpha$ overexpression on MMPs in choriocarcinoma cells. (A) HIF-1 $\alpha$ overexpression upregulates MMP2 and MMP9 expression can be abrogated by DAPT in JAR cells $(\mathrm{P}<0.01)$. (B) HIF-1 $\alpha$ overexpression upregulates MMP2 and MMP9 expression can be abrogated by DAPT in JEG-3 cells $(\mathrm{P}<0.01)$.

Because there were multiple metastatic lesions found in the lungs, positive signals from isolated lesions were integrated for the measurement of photon counts in each mouse. The DMSO groups showed that the levels of detectable EGFP signals for the lv-HIF-1 $\alpha$ mice were stronger than lv-NC mice. In contrast, $80 \%(4 / 5, \mathrm{HIF}-1 \alpha)$ and $60 \%(3 / 5, \mathrm{lv}-\mathrm{NC})$ of mice treated with DAPT had positive signals. In contrast to increased areas of detectable EGFP in DMSO-treated lv-HIF- $1 \alpha$ and lv-NC mice, the EGFP-positive areas were limited in mice with DAPT treatment (Fig. 8). No side effect was observed throughout the experiments in the tested mice.

\section{Discussion}

Choriocarcinoma is highly malignant and aggressive epithelial tumor type comprising a series of heterogeneous diseases arising from gestational trophoblasts that form the placenta. It becomes a conspicuous tumor when it metastasizes to affected organs, which induces symptoms such as shortness of breath from lung involvement. Although $\mathrm{CC}$ is highly responsive to chemotherapy with an overall survival rate of $>90 \%$, the mechanisms for metastasis and resistance to conventional chemotherapy is still unclear.

HIF- $1 \alpha$ as a potential hypoxia marker is associated with carcinogenesis and metastasis in various solid tumors $(26,31,32)$. Since associated with chemotherapy failure, HIF-1 $\alpha$ could be an attractive therapeutic strategy crucial for tumor growth $(33,34)$. Although HIF-1 $\alpha$ has been explored in several other gynecological cancers, scarce date exist on the role of HIF-1 $\alpha$ in CC. In this study, we first detected the expression of HIF-1 $\alpha$ in several cell lines, and found that the expression of HIF-1 $\alpha$ in human choriocarcinoma cell lines was higher than that in the immortalized normal human EVT cell line (HTR8). The data show that overexpression of HIF-1 $\alpha$ is emerging as an significant factor in carcinogenesis on the molecular level in CC. Generally, HIF-1 $\beta$ is regarded as constitutively expressed and being present in excess within the cell $(4,35)$. However, several studies described that HIF-1 $\beta$ was upregu- 
A
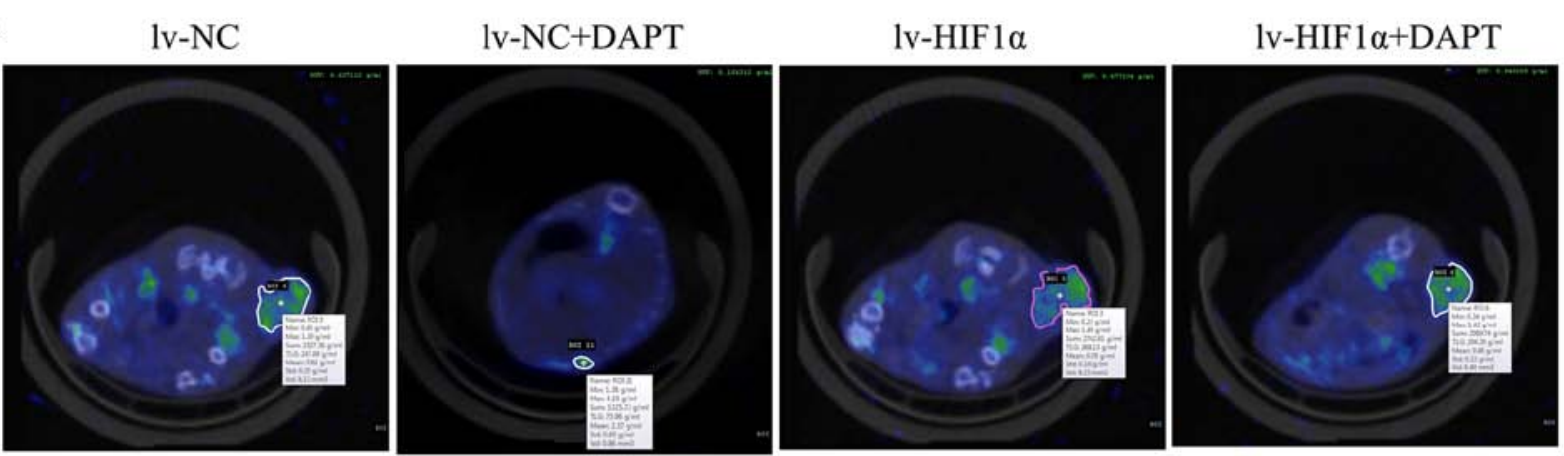

B

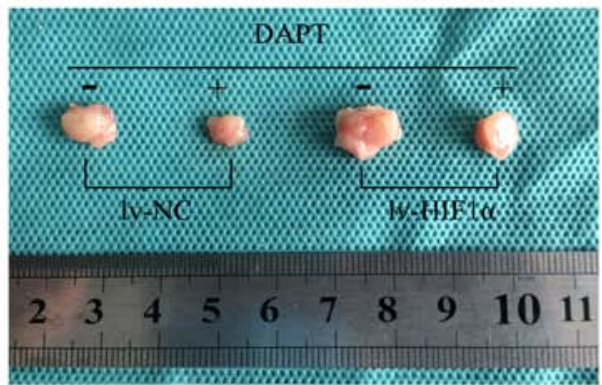

C

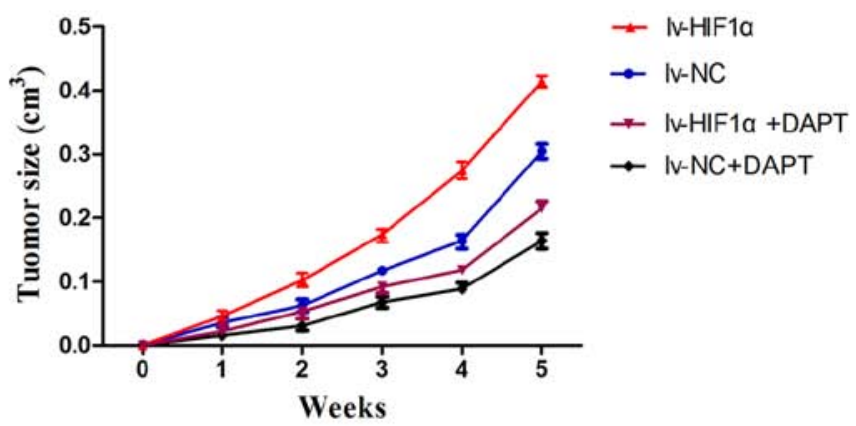

Figure 7. Effects of Notch signaling inhibitor on choriocarcinoma growth and metabolic activity in vivo. (A) ${ }^{18} \mathrm{~F}-\mathrm{FDG}$ binding in subcutaneous xenografts from SA-PET/CT of lv-NC, lv-NC/DAPT, lv-HIF-1 $\alpha$ and lv-HIF-1 $\alpha$ /DAPT group. (B) Representative images of choriocarcinoma xenografts from lv-NC, lv-NC/ DAPT, lv-HIF-1 $\alpha$ and lv-HIF-1 $\alpha /$ DAPT group. (C) Xenograft size in lv-NC, lv-NC/DAPT, lv-HIF-1 $\alpha$ and lv-HIF-1 $\alpha$ /DAPT group were monitored over time $(\mathrm{P}<0.01)$.
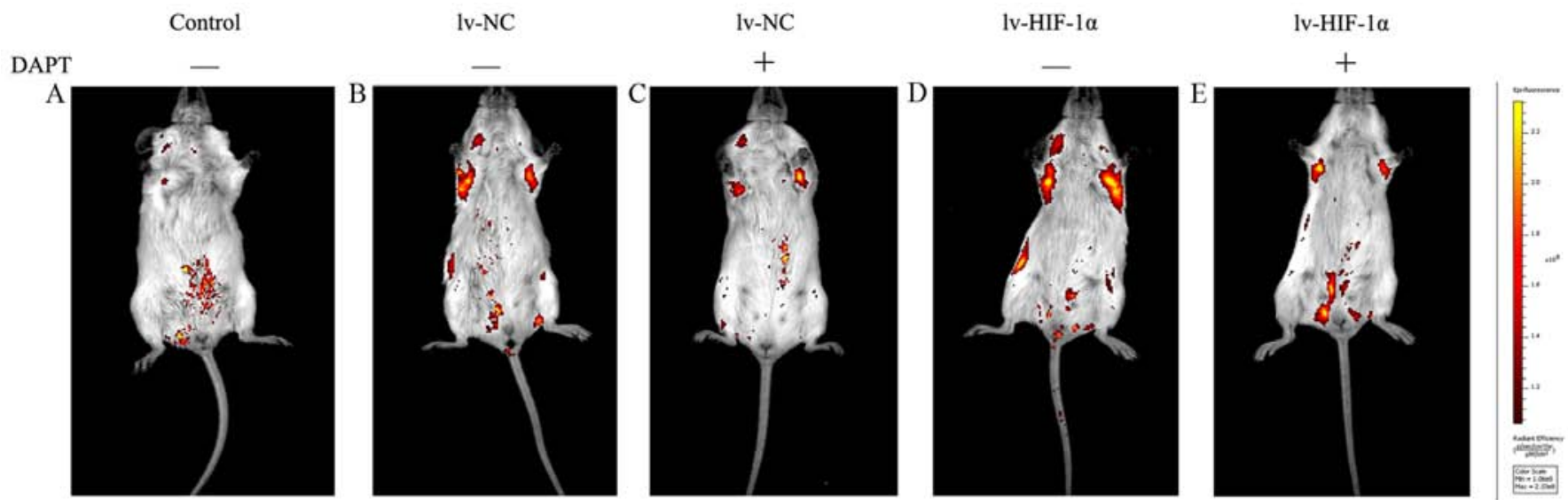

Figure 8. Effects of Notch signaling inhibitor on choriocarcinoma invasion and metastasis in vivo. Representative images of choriocarcinoma xenografts from control, lv-NC, lv-NC/DAPT, lv-HIF-1 $\alpha$ and lv-HIF-1 $\alpha /$ DAPT group. Imaging data were evaluated by IVIS at day 30 after cell injection.

lated in a HIF-1 $\alpha$-dependent manner after treatment with the hypoxia-mimetic cobalt chloride $\left(\mathrm{CoCl}_{2}\right)$ or exposure to hypoxia on both RNA and protein levels $(26,36,37)$. To inspect the hypothesis that the upregulation of HIF-1 $\beta$ might be mediated by HIF-1 $\alpha$, we demonstrated that overexpression of HIF-1 $\alpha$ was upregulated HIF-1 $\beta$-dependently. The data confirm the leading role of HIF-1 $\alpha$ among HIF subunits.

In cell culture, animal models and human specimen experiments, the evidence for EMT with increased invasion and metastasis is irresistible (38). In this study, the inseparable connection between hypoxia and EMT has been recognized. Here we indicated that HIF-1 $\alpha$ evidently correlated with more aggressive and invasive behavior accompanied by the EMT switch.

Notch signaling acts as a tumor promoter or a suppressor depending on the cell type and context. As the first evidence, Notch signaling is considered the main trigger of T-ALL (39). However, Notch activation in bladder cancer cells suppresses proliferation both in vitro and in vivo (40). Recently, various research, respectively, indicated that Notch signaling potentially mediated molecular mechanisms underlying HIF-dependent regulation of the EMT in solid tumors. To our knowledge, we show the involvement of the Notch pathway during the process of HIF-1 $\alpha$-induced 
switch of EMT in choriocarcinoma for the first time. Our finding that the Notch signaling pathway respond to HIF-1 $\alpha$ at various levels is consistent with some other studies $(22,33)$. As $\gamma$-secretase inhibitor, DAPT interfers with Notch intracellularly and NICD synthesis is a powerful blocker of Notch activity. In our study, following treatment of $\mathrm{CC}$ cell lines with DAPT, the expression of N1ICD and downstream Hes1, was significantly decreased, whereas, E-cadherin, CK18 and CK19 were upregulated. In addition, through the suppression of Notch signaling, a crucial target reducing migration and invasion, may be the upregulation of E-cadherin, CK18 and CK19 expression and downregulation of MMPs, such as MMP2 and MMP9 during the acquisition of the epithelial phenotype, which recovers cell-cell adhesion and stabilizes the epithelial architecture. Above all, HIF- $1 \alpha$-induced EMT requires Notch signaling and the decreased endogenous Notch signaling blocked cells to EMT. Moody et al reported that upregulation of Snail-1 induced metastasis and poor prognosis, whereas silencing of Snail-1 suppressed tumor growth and invasiveness (41). In keeping with this notion, Sahlgren et al showed that Notch regulated expression of Snail-1 in two different but synergistic ways (22). Coincidentally, Snail-1, which is activated during the acquisition of EMT was downregulated in CC cells treated with DAPT.

The most common metastatic site of $\mathrm{CC}$ is the lungs, which are affected in $>80 \%$ patients and PET/CT scanning and can aid in identifying sites of active disease, and select patients with solitary lesions who may benefit from surgical resection of chemotherapy-resistant metastases $(42,43) .{ }^{18} \mathrm{~F}$-FDG SA-PET is widely used for non-invasive in vivo therapy assessment in cancer research (44). Using the present in vivo model of CC, SA-PET/CT and IVIS system, we further confirmed important roles of Notch1 signaling in overexpressed HIF-1 $\alpha$ cell invasion and metastasis. Consistent with in vitro studies, suppression of endogenous Notch1 signaling by DAPT not only led to inhibited CC growth and metabolic activity, but also decreased their metastasis to lung, accompanied by suppressed growth of metastatic tumors. Leong et al indicated that blocking Notch signaling inhibits tumor growth and metastasis in an in vivo tumor model (21). These findings indicated that Notch signaling is a valuable target with a therapeutic potential for both early and advanced stages of CC.

In conclusion, this study demonstrated that the Notch1 signaling pathway is closely associated with the invasion and metastasis of CC. Furthermore, the results demonstrated that the suppression of Notch1 with the $\gamma$-secretase inhibitor restrains the invasion and metastasis of $\mathrm{CC}$ by inhibiting EMT. Therefore, purification of Notch inhibitors and a more local containment may be an effective way toward improving therapy.

\section{Acknowledgement}

This study was supported by the National Natural Science Foundation of China (no. 81172489).

\section{References}

1. Cheung AN, Zhang HJ, Xue WC and Siu MK: Pathogenesis of choriocarcinoma: Clinical, genetic and stem cell perspectives. Future Oncol 5: 217-231, 2009.
2. Semenza GL: HIF-1 and tumor progression: Pathophysiology and therapeutics. Trends Mol Med 8 (Suppl): S62-S67, 2002.

3. Shen G, Li X, Jia YF, Piazza GA and Xi Y: Hypoxia-regulated microRNAs in human cancer. Acta Pharmacol Sin 34: 336-341, 2013.

4. Lee JW, Bae SH, Jeong JW, Kim SH and Kim KW: Hypoxiainducible factor (HIF-1)alpha: Its protein stability and biological functions. Exp Mol Med 36: 1-12, 2004.

5. Bruick RK: Oxygen sensing in the hypoxic response pathway: Regulation of the hypoxia-inducible transcription factor. Genes Dev 17: 2614-2623, 2003.

6. Semenza GL: Hypoxia-inducible factor 1: Oxygen homeostasis and disease pathophysiology. Trends Mol Med 7: 345-350, 2001.

7. Jiang J, Tang YL and Liang XH: EMT: A new vision of hypoxia promoting cancer progression. Cancer Biol Ther 11: 714-723, 2011.

8. Christofori G: New signals from the invasive front. Nature 441: 444-450, 2006

9. Ombrato L and Malanchi I: The EMT universe: Space between cancer cell dissemination and metastasis initiation. Crit Rev Oncog 19: 349-361, 2014.

10. Lee JM, Dedhar S, Kalluri R and Thompson EW: The epithelialmesenchymal transition: New insights in signaling, development, and disease. J Cell Biol 172: 973-981, 2006.

11. Zhou X, Hu Y, Dai L, Wang Y,Zhou J, Wang W, Di W and Qiu L: MicroRNA-7 inhibits tumor metastasis and reverses epithelialmesenchymal transition through AKT/ERK1/2 inactivation by targeting EGFR in epithelial ovarian cancer. PLoS One 9: e96718, 2014

12. Ponnusamy MP, Lakshmanan I, Jain M, Das S, Chakraborty S, Dey P and Batra SK: MUC4 mucin-induced epithelial to mesenchymal transition: A novel mechanism for metastasis of human ovarian cancer cells. Oncogene 29: 5741-5754, 2010.

13. Techasen A, Namwat N,Loilome W, Bungkanjana P, Khuntikeo N, Puapairoj A, Jearanaikoon P, Saya $\mathrm{H}$ and Yongvanit P: Tumor necrosis factor- $\alpha$ (TNF- $\alpha$ ) stimulates the epithelial-mesenchymal transition regulator Snail in cholangiocarcinoma. Med Oncol 29: 3083-3091, 2012

14. Kim H, Choi GH, Na DC, Ahn EY, Kim GI, Lee JE, Cho JY, Yoo JE, Choi JS and Park YN: Human hepatocellular carcinomas with 'Stemness'-related marker expression: Keratin 19 expression and a poor prognosis. Hepatology 54: 1707-1717, 2011.

15. Barrallo-Gimeno A and Nieto MA: The Snail genes as inducers of cell movement and survival: Implications in development and cancer. Development 132: 3151-3161, 2005.

16. Artavanis-Tsakonas S, Rand MD and Lake RJ: Notch signaling: Cell fate control and signal integration in development. Science 284: 770-776, 1999.

17. Kadesch T: Notch signaling: The demise of elegant simplicity. Curr Opin Genet Dev 14: 506-512, 2004.

18. Gustafsson MV, Zheng X, Pereira T, Gradin K, Jin S, Lundkvist J, Ruas JL, Poellinger L, Lendahl U and Bondesson M: Hypoxia requires notch signaling to maintain the undifferentiated cell state. Dev Cell 9: 617-628, 2005.

19. Chen Y, De Marco MA, Graziani I, Gazdar AF, Strack PR, Miele L and Bocchetta M: Oxygen concentration determines the biological effects of NOTCH-1 signaling in adenocarcinoma of the lung. Cancer Res 67: 7954-7959, 2007.

20. Fang Y, Yu S, Ma Y, Sun P, Ma D, Ji C and Kong B: Association of D114/notch and HIF-1 $\alpha$-VEGF signaling in the angiogenesis of missed abortion. PLoS One 8: e70667, 2013.

21. Leong KG, Niessen K, Kulic I, Raouf A, Eaves C, Pollet I and Karsan A: Jagged1-mediated Notch activation induces epithelialto-mesenchymal transition through Slug-induced repression of E-cadherin. J Exp Med 204: 2935-2948, 2007.

22. Sahlgren C, Gustafsson MV, Jin S, Poellinger L and Lendahl U: Notch signaling mediates hypoxia-induced tumor cell migration and invasion. Proc Natl Acad Sci USA 105: 6392-6397, 2008.

23. Chen J, Imanaka N, Chen J and Griffin JD: Hypoxia potentiates Notch signaling in breast cancer leading to decreased E-cadherin expression and increased cell migration and invasion. Br J Cancer 102: 351-360, 2010.

24. Bedogni B, Warneke JA, Nickoloff BJ, Giaccia AJ and Powell MB: Notchl is an effector of Akt and hypoxia in melanoma development. J Clin Invest 118: 3660-3670, 2008.

25. Baddela VS, Baufeld A, Yenuganti VR, Vanselow J and Singh D: Suitable housekeeping genes for normalization of transcript abundance analysis by real-time RT-PCR in cultured bovine granulosa cells during hypoxia and differential cell plating density. Reprod Biol Endocrinol 12: 118, 2014. 
26. Guan Z, Ding C, Du Y, Zhang K, Zhu JN, Zhang T, He D, Xu S, Wang $X$ and Fan J: HAF drives the switch of HIF-1 $\alpha$ to HIF-2 $\alpha$ by activating the NF- $\mathrm{KB}$ pathway, leading to malignant behavior of T24 bladder cancer cells. Int J Oncol 44: 393-402, 2014.

27. Xie M, He CS, Wei SH and Zhang L: Notch-1 contributes to epidermal growth factor receptor tyrosine kinase inhibitor acquired resistance in non-small cell lung cancer in vitro and in vivo. Eur J Cancer 49: 3559-3572, 2013.

28. Yang Y, Yan X, Duan W, Yan J, Yi W, Liang Z, Wang N, Li Y, Chen W, Yu S, et al: Pterostilbene exerts antitumor activity via the Notch1 signaling pathway in human lung adenocarcinoma cells. PLoS One 8: e62652, 2013.

29. Zhang S, Yang Y, Liang Z, Duan W, Yang J, Yan J, Wang N, Feng W, Ding M, Nie Y, et al: Silybin-mediated inhibition of Notch signaling exerts antitumor activity in human hepatocellular carcinoma cells. PLoS One 8: e83699, 2013.

30. Aboagye EO: Positron emission tomography imaging of small animals in anticancer drug development. Mol Imaging Biol 7: 53-58, 2005.

31. Semenza GL: HIF-1 mediates metabolic responses to intratumoral hypoxia and oncogenic mutations. J Clin Invest 123 3664-3671, 2013

32. Maroni P, Matteucci E, Drago L, Banfi G, Bendinelli P and Desiderio MA: Hypoxia induced E-cadherin involving regulators of Hippo pathway due to HIF-1alpha stabilization/nuclear translocation in bone metastasis from breast carcinoma. Exp Cell Res 30: 287-299, 2015.

33. Seeber LM, Horrée N, Vooijs MA, Heintz AP, van der Wall E, Verheijen RH and van Diest PJ: The role of hypoxia inducible factor-1alpha in gynecological cancer. Crit Rev Oncol Hematol 78: 173-184, 2011.

34. Miyazawa M, Yasuda M, Fujita M, Hirasawa T, Kajiwara H, Hirabayashi K, Ogane N, Shimizu M, Asanuma H, Murakami M, et al: Association of hypoxia-inducible factor-1 expression with histology in epithelial ovarian tumors: A quantitative analysis of HIF-1. Arch Gynecol Obstet 279: 789-796, 2009.
35. Semenza GL: Oxygen homeostasis. Wiley Interdiscip Rev Syst Biol Med 2: 336-361, 2010.

36. Mandl M, Kapeller B, Lieber R and Macfelda K: Hypoxiainducible factor- $1 \beta$ (HIF-1 $\beta$ ) is upregulated in a HIF-1 $\alpha$-dependent manner in 518A2 human melanoma cells under hypoxic conditions. Biochem Biophys Res Commun 434: 166-172, 2013.

37. Chilov D, Camenisch G, Kvietikova I, Ziegler U, Gassmann M and Wenger RH: Induction and nuclear translocation of hypoxiainducible factor-1 (HIF-1): Heterodimerization with ARNT is not necessary for nuclear accumulation of HIF-1alpha. J Cell Sci 112: 1203-1212, 1999.

38. Liang X: EMT: New signals from the invasive front. Oral Oncol 47: 686-687, 2011.

39. Weng AP, Ferrando AA, Lee W, Morris JP IV, Silverman LB, Sanchez-Irizarry C, Blacklow SC, Look AT and Aster JC: Activating mutations of NOTCH1 in human T cell acute lymphoblastic leukemia. Science 306: 269-271, 2004.

40. Rampias T, Vgenopoulou P, Avgeris M, Polyzos A, Stravodimos K, Valavanis C, Scorilas A and Klinakis A: A new tumor suppressor role for the Notch pathway in bladder cancer. Nat Med 20: 1199-1205, 2014.

41. Moody SE, Perez D, Pan TC, Sarkisian CJ, Portocarrero CP, Sterner CJ, Notorfrancesco KL, Cardiff RD and Chodosh LA: The transcriptional repressor Snail promotes mammary tumor recurrence. Cancer Cell 8: 197-209, 2005.

42. Dhillon T, Palmieri C, Sebire NJ, Lindsay I, Newlands ES, Schmid P, Savage PM, Frank J and Seckl MJ: Value of whole body ${ }^{18} \mathrm{FDG}-\mathrm{PET}$ to identify the active site of gestational trophoblastic neoplasia. J Reprod Med 51: 879-887, 2006.

43. Froeling FE and Seck1 MJ: Gestational trophoblastic tumours: An update for 2014. Curr Oncol Rep 16: 408, 2014.

44. Lasnon C, Dugue AE, Briand M, Blanc-Fournier C, Dutoit S, Louis MH and Aide N: NEMA NU 4-optimized reconstructions for therapy assessment in cancer research with the Inveon small animal PET/CT system. Mol Imaging Biol 17: 403-412, 2015. 